\title{
De novo head and neck cancer after liver transplant with antibody-based immunosuppression induction
}

\author{
Ryan C. Graham, ${ }^{1}$ Jeffrey S. Mella, ${ }^{1}$ Richard S. Mangus, ${ }^{1}$
}

1. Transplant Division, Department of Surgery, Indiana University School of Medicine

Email Addresses:

Ryan Graham - ryangrah@iupui.edu

Jeffrey Mella - jeffmella@gmail.com

Richard Mangus-rmangus@iupui.edu

Word count:

$\begin{array}{llll}\text { Abstract } & 230 & \text { Text } & 2219 \\ \text { Tables } & 4 & \text { Figures } & 1\end{array}$

Corresponding author/Reprints:

Dr. Richard S. Mangus, MD MS FACS

Department of Surgery, Indiana University School of Medicine

550 N University Blvd, Room 4601, Indianapolis, Indiana 46202-5250

Phone: (317) 944-4370

Fax: (317) 948-3268

E-mail: rmangus@iupui.edu

This is the author's manuscript of the article published in final edited form as:

Graham, R. C., Mella, J. S., \& Mangus, R. S. (2018). De novo head and neck cancer after liver transplant with antibody-based immunosuppression induction. Transplantation Proceedings. https://doi.org/10.1016/j.transproceed.2018.06.033 


\begin{abstract}
Background: Powerful antibody-based immunosuppression induction is now used routinely during organ transplantation, and may place patients at even higher risk of post-transplant cancer.

Materials and Methods: Incidence of de-novo head and neck cancer was extracted from the records of 1685 consecutive adult, deceased donor liver transplant recipients with a minimum 1-year follow-up from 2001 to 2015 . There were 121 patients positively identified as having developed de-novo head and neck cancer post-liver transplant. Records of these patients were analyzed to determine demographics, history of cancer pre-liver transplant, de-novo cancer type and location, treatment modalities, and alcohol and tobacco exposure.
\end{abstract}

Results: Of the 121 patients who developed cancer of the head and neck (7\%), there were 103 cutaneous $(6 \%)$ and 25 non-cutaneous (1\%). For non-cutaneous cancers, factors associated with increased risk of cancer included alcohol abuse ( $\mathrm{p}<0.001)$, any smoking history $(\mathrm{p}=0.05)$, and increasing exposure to tobacco $(\mathrm{p}<0.01)$. Ten-year Cox regression patient survival demonstrates a survival disadvantage for patients who develop non-cutaneous cancer $(\mathrm{p}=0.06)$, but a survival advantage for patients who develop cutaneous cancer $(\mathrm{p}<0.01)$.

Conclusions: The incidence and pattern of head and neck cancer in this population of liver transplant patients was similar to those published previously, suggesting that induction immunosuppression does not increase risk of these types of cancers. Long term survival was worse for patients with non-cutaneous cancers, but better for those with cutaneous cancers, though the reason is unclear. 


\section{Introduction}

In solid organ transplant patients, there is increased risk for de novo malignancies related to chronic immunosuppression. ${ }^{1,2}$ In recent years, there is increased use of powerful antibody therapies which are employed to rapidly induce an immunosuppressed state at the time of transplant. ${ }^{3-5}$ Immunosuppression induction has become standard of care at many centers and may be associated with less rejection and improved graft survival. ${ }^{6}$ However, it has been suggested that augmenting post-transplant immunosuppression predisposes transplant recipients to an even greater risk of de novo malignancy. Transplant patients are known to have an increased risk for many types of tumors, especially dermatologic cancers frequently found in the head and neck region. ${ }^{7-15}$

One group of patients at particular risk for post-transplant cancer are liver transplant patients because of the high incidence of alcohol abuse and tobacco use among this population. ${ }^{16}$ Chronic exposure to these noxious substances has led to several published reports. ${ }^{7,8,14}$ This study seeks to determine the incidence of head and neck cancer in a large population of liver transplant recipients who all received antibody-based immunosuppression induction.

Demographic and behavioral factors associated with tumor formation will be determined. Further, the subtypes of identified cancers will be noted, along with therapies and long-term outcomes.

\section{Materials and Methods}

This study is a retrospective review of deceased donor, orthotopic liver transplant patients at a single, large U.S. center over a 15-year time period (2001 to 2015). Minimum follow-up was 1-year, with median death-censored follow-up time of 72 months. Extracted data came from the 
comprehensive transplant recipient registry at our center, and individual written and electronic medical records. Recipient inclusion criteria included all transplant recipients age 18 years and older receiving a deceased donor liver allograft. Graft and patient survival data were collected from the transplant database which is updated on a regular basis. This database also includes laboratory values and significant medical events post-transplant for all transplant recipients.

All patients were listed for transplantation according to standard procedures and protocols as established by our center and by the United Network for Organ Sharing (UNOS). Patients are transplanted at all centers according to their model for end-stage liver disease (MELD) score, which is calculated using the serum total bilirubin, international normalized ratio (INR) and serum creatinine. In patients receiving re-transplantation, the analysis included only data for the first transplant and all patients were listed only once in the final data set. All patients were included in the final survival analysis without any exclusions for extenuating circumstances such as unexpected death or graft loss unrelated to the allograft or the transplant procedure (intention to treat). Data collection included patient and donor demographics and etiology of liver disease. A large portion of this data had been collected previously and is maintained in a comprehensive transplant center registry.

This study undertook a detailed review of the pre- and post-transplant medical records of all liver transplant recipients to determine the pre-transplant history of cancer as well as the posttransplant de novo incidence of cancer. Transplant outcomes included de novo cancer incidence of any type, recurrence of hepatocellular carcinoma (HCC) in patients with $\mathrm{HCC}$ on liver explant pathology, overall patient survival, cancer free survival, and cause-specific mortality. All occurrences of cancer incidence or patient death were included in the final analysis regardless of 
the etiology, circumstances or co-morbidities. There was no specific cancer surveillance protocol instituted for this study, but the prevailing standard of care is followed by our center. Cancer therapies included standard of care according to the site and type of cancer. The original surgical and medical records were reviewed to determine procedures performed and therapies administered.

The immunosuppression protocol at this center has been described previously and includes induction therapy with rabbit anti-thymocyte globulin and steroids, followed by standard maintenance with tacrolimus monotherapy. ${ }^{4,6}$ All patients received 3 doses of the antibody induction agent with a total dose of $6 \mathrm{mg} / \mathrm{kg}$. These doses are administered on postoperative days 2, 4 and 6. Over half of the patients also received a single dose of rituximab, an anti-B-cell agent $\left(150 \mathrm{mg} / \mathrm{m}^{2}\right)$. Rituximab was added to the induction protocol in an attempt to prevent donor specific antibody formation. Goal tacrolimus levels ranged from 6-10ng/dL, depending upon the baseline serum creatinine and underlying disease of the recipient. The immunosuppression protocol was stable throughout the study period. Experienced transplant hepatologists follow all patients post-transplant and provide routine screening for breast, colon, prostate, and cervical cancer. Patients are instructed to have a thorough dermatologic exam once yearly by a medical professional as surveillance for skin cancer. Any diagnosis of de novo or recurrent cancer required tissue confirmation with reading by a pathologist.

Statistical testing was performed on SPSS software (IBM SPSS Statistics Version 24, IBM Corporation, Armonk, New York, USA). Standard statistical testing was utilized for continuous and categorical variables, as indicated. The Cox proportional hazards model was constructed using a direct entry method. Co-variates were included in the final model for 
variables with $\mathrm{p}$-value $<0.10$. Retrospective analysis of data for liver transplant patients at our centers was reviewed and approved by the institutional review board of the Indiana University School of Medicine.

\section{Results}

There were 1685 patients who met inclusion criteria and had complete data for analysis. Median follow up was 72 months, ranging from 12 to 185 months. Of these liver transplant recipients, $121(7 \%)$ were found to have 128 head and neck cancers (25 non-cutaneous and 103 cutaneous). [Table 1] Patients with de novo cutaneous cancers were more likely to be male, White, older and have a lower model for end stage liver disease (MELD) score (all with p-value $<0.01)$. Patients with de novo non-cutaneous head and neck cancers were similar for all demographics except for body mass index (BMI), in which case the patients with tumor had a lower median BMI $(\mathrm{p}=0.02)$. The results for risk of any head and neck cancer mirrored those of the cutaneous cancer group. In a bivariate stratified analysis of these factors, the rate of cutaneous head and neck cancer in males was twice that seen in females $(p<0.01)$. [Table 2] Cutaneous cancers were only seen in White patients ( $\mathrm{p}=0.001)$, with an increasing risk of this type of cancer with increasing age $(\mathrm{p}<0.001)$ and lower MELD score $(\mathrm{p}=0.01)$. Among patient with non-cutaneous head and neck cancer, there was no association with any of these factors. Again, the risk of any cancer mirrored those of the cutaneous cancer group.

Subgroup analysis was performed to assess the association between known risk factors for cancer and the incidence of head and neck cancer in this cohort. [Table 3] The incidence of cutaneous cancer was not associated with a history of known alcohol abuse, nor with a history of any previous cancer. There was no association between cutaneous cancer and any history of 
smoking, but there was a higher incidence for those patients with greater than 40 pack-years of smoking $(\mathrm{p}<0.01)$. Non-cutaneous cancers were associated with alcohol abuse $(72 \%$ versus $37 \%$ $\mathrm{p}<0.001)$ and any history of smoking $(68 \%$ versus $51 \%, \mathrm{p}=0.05)$, as well as a trend of increasing risk with increased total tobacco exposure $(\mathrm{p}=<0.01)$. Patients with a history of any cancer before liver transplant are not at increased risk for head and neck cancer post-liver transplant.

A summary of head and neck cancer subtypes and locations is provided. [Table 4] For cutaneous cancers, there were 57 squamous cell (3\%, SCC), 48 basal cell (3\%, BCC) and 1 basosquamous cancer $(<1 \%$, BSC). There were 5 patients with melanoma $(<1 \%)$. The most commonly involved sites included the nose (25), cheek/mandible (22), ear (18), forehead (18), scalp (15) and the neck (15). Of the 5 patients with melanoma, 4 melanomas were found in the scalp (1), temple (1) and neck (2). One melanoma was treated at an outside provider, and specific facial location was unavailable. Treatment for all cutaneous cancer included either excision (97\%) or cryotherapy (4\%), or both. Of the 5 patients with melanoma, all underwent simple excision (two with sentinel lymph node sampling), and one required subsequent neck dissection. At the time of this manuscript, 15 patients with cutaneous head and neck cancer (alone) had died (15\%), but only two of these deaths were directly related to the cancer (both were metastatic melanoma).

For non-cutaneous cancers, there were 25 cases, most commonly found in the larynx (7), oral cavity (5), hypopharynx (5), and oropharynx (4). One patient was diagnosed simply with "throat cancer" at an outside facility, and died shortly thereafter with no other information available. Of the 24 non-cutaneous cancer patients with available records, 7 also had cutaneous cancers, of which 5 were squamous cell, 1 was basal cell, and 1 was both basal and squamous 
cell carcinoma. Cancer type in these 24 patients included squamous cell (18), thyroid cancer (3), and "throat cancer" (2). More radical therapies were commonly performed for these cancers, including neck dissection (8), laryngectomy (5), flap surgery (4), parotidectomy (4), thyroidectomy (3), glossectomy (3), and auriculectomy (1). There were 13 patients who received chemotherapy (54\%) and 18 who received radiation therapy (75\%), while 12 received both chemo- and radiation therapy (50\%). At the time of this manuscript, 11 of the 25 patients with non-cutaneous head and neck cancer had died (44\%), all related to complications of their cancer.

Cox regression analysis of 10-year patient survival was performed. For patients who developed non-cutaneous head and neck cancer, there was a decreased survival of $14 \%(66 \%$ versus $52 \%, \mathrm{p}=0.06$ ) when compared to all other liver transplant patients in the cohort. [Figure 1b] However, for patients with cutaneous head and neck cancer, there was an increased survival of $15 \%$ ( $80 \%$ versus $65 \%, \mathrm{p}<0.01)$. [Figure 1a] The significant covariates included in the regression model included recipient and donor age, MELD score, hepatitis $\mathrm{C}$ infection, donation after cardiac death donor, and year of transplant ( $\mathrm{p}<0.05$ for each). Because of the unexpected finding of improved survival in the group with cutaneous head and neck cancer, additional variables were tested in the model including gender, race and tobacco use. Each of these additional variables was found to be non-significant.

\section{Discussion}

The incidence of head and neck cancer in this population of liver transplant patients who received antibody-based immunosuppression induction was similar to that reported in previous publications of head and neck cancer in immunosuppressed patients, which is higher than that of the general population. ${ }^{17-19}$ This finding supports the validity of the data from this study and 
suggests that induction immunosuppression does not place patients at higher risk than other immunosuppressed transplant patients. Most studies addressing head and neck cancers in transplant patients report data collected in countries outside the United States (U.S.), where tumor registries are more easily cross-matched. ${ }^{7-11,13,14}$ The reported incidence of all head and neck cancers at most centers is $6-7 \%$, while non-cutaneous head and neck cancers are $1 \%$. U.S. reports show lower rates, but the identification of tumors is likely less complete. ${ }^{12,15}$ The data from the present study are similar to the non-U.S. results, with a thorough review of all patients and a median follow up time of 72 months.

There was no association between non-cutaneous head and neck cancer and patient demographics. For cutaneous cancers, male gender, White race, increasing age and lower MELD score were associated with cancer incidence. However, this study did find an increased risk of both cutaneous and non-cutaneous cancers to be associated with increased tobacco exposure, and non-cutaneous cancers were associated with any tobacco use and with alcohol abuse. Unfortunately, sun exposure could not be assessed in this population. Again, these results validate the findings of this study, as these outcomes are similar to those previously reported. It is important to note that tobacco use and alcohol abuse are common in the liver transplant population. This fact places this particular population at higher risk for non-cutaneous head and neck cancers because of the combined risk of lifetime tobacco and alcohol exposure and immunosuppression.

A detailed multivariate survival analysis was performed. As expected, the small number of patients who developed non-cutaneous head and neck cancer did have lower survival at 10year. However, even this group of high risk patients achieved a 52\% 10-year survival. This 
finding could be contributed to close surveillance and early detection, allowing for aggressive therapy to optimize survival. The survival advantage among the 103 patients who developed cutaneous head and neck cancer is unexpected. Further analysis of this $15 \%$ survival advantage $(\mathrm{p}<0.01)$ did not uncover a group difference to account for the result.

The higher prevalence of malignancies in the post-transplant population is related to the loss of immunosurveillance that is so critical to preventing growth and progression of cancer cells in the human body. Induction immunosuppression rapidly achieves a more profound immunosuppressed state within a very short time period. However, over the period of several months, the initial induction resolves and the patient returns to a level of immunosuppression dictated only by the maintenance immunosuppression. Centers employing immunosuppression induction frequently maintain lower maintenance immunosuppression as the view the early posttransplant period as the most critical to preventing rejection. De novo cancers occur months to years after transplant and may be affected more by the choice of maintenance immunosuppression rather than the use of an induction protocol. Results from this study suggest that in a large number of patients receiving early immunosuppression induction, the risk of head and neck cancer was similar to that seen in previous reports without induction. 


\section{References}

1. Carenco C, Faure S, Herrero A, et al. Incidence of solid organ cancers after liver transplantation: comparison with regional cancer incidence rates and risk factors. Liver Int. 2015;35(6): 1748-1755.

2. Carenco C, Faure S, Ursic-Bedoya J, Herrero A, Pageaux GP. Solid, non-skin, post-liver transplant tumors: Key role of lifestyle and immunosuppression management. World J Gastroenterol. 2016;22(1): 427-434.

3. Eason JD, Loss GE, Blazek J, Nair S, Mason AL. Steroid-free liver transplantation using rabbit antithymocyte globulin induction: results of a prospective randomized trial. Liver Transpl. 2001;7(8): 693-697.

4. Tector AJ, Fridell JA, Mangus RS, et al. Promising early results with immunosuppression using rabbit antithymocyte globulin and steroids with delayed introduction of tacrolimus in adult liver transplant recipients. Liver Transpl. 2004;10(3): 404-407.

5. Watson CJ, Bradley JA, Friend PJ, et al. Alemtuzumab (CAMPATH $1 \mathrm{H}$ ) induction therapy in cadaveric kidney transplantation--efficacy and safety at five years. Am J Transplant. 2005;5(6): 1347-1353.

6. Mangus RS, Fridell JA, Vianna RM, Kwo PY, Chen J, Tector AJ. Immunosuppression induction with rabbit antithymocyte globulin with or without rituximab in 1000 liver transplant patients with long-term follow-up. Liver Transpl. 2012;18(7): 786-795.

7. Coordes A, Albers AE, Lenarz $M$, et al. Incidence and long-term survival of patients with de novo head and neck carcinoma after liver transplantation. Head Neck. 2016;38(5): 707-714.

8. Piselli $P$, Burra $P$, Lauro A, et al. Head and neck and esophageal cancers after liver transplant: results from a multicenter cohort study. Italy, 1997-2010. Transpl Int. 2015;28(7): 841-848.

9. Ohman J, Rexius H, Mjornstedt L, et al. Oral and lip cancer in solid organ transplant patients--a cohort study from a Swedish Transplant Centre. Oral Oncol. 2015;51(2): 146-150.

10. Rabinovics N, Mizrachi A, Hadar T, et al. Cancer of the head and neck region in solid organ transplant recipients. Head Neck. 2014;36(2): 181-186.

11. Nelissen C, Lambrecht M, Nevens F, et al. Noncutaneous head and neck cancer in solid organ transplant patients: single center experience. Oral Oncol. 2014;50(4): 263-268.

12. Deeb R, Sharma S, Mahan M, et al. Head and neck cancer in transplant recipients. Laryngoscope. 2012;122(7): 1566-1569.

13. Makitie AA, Lundberg M, Salmela K, Kyllonen L, Pukkala E. Head and neck cancer in renal transplant patients in Finland. Acta Otolaryngol. 2008;128(11): 1255-1258.

14. Scheifele C, Reichart PA, Hippler-Benscheidt M, Neuhaus P, Neuhaus R. Incidence of oral, pharyngeal, and laryngeal squamous cell carcinomas among 1515 patients after liver transplantation. Oral Oncol. 2005;41(7): 670676.

15. Preciado DA, Matas A, Adams GL. Squamous cell carcinoma of the head and neck in solid organ transplant recipients. Head Neck. 2002;24(4): 319-325.

16. Schrem H, Kurok M, Kaltenborn A, et al. Incidence and long-term risk of de novo malignancies after liver transplantation with implications for prevention and detection. Liver Transpl. 2013;19(11): 1252-1261.

17. Engels EA, Pfeiffer RM, Fraumeni JF, Jr., et al. Spectrum of cancer risk among US solid organ transplant recipients. JAMA. 2011;306(17): 1891-1901.

18. Sampaio MS, Cho YW, Qazi Y, Bunnapradist S, Hutchinson IV, Shah T. Posttransplant malignancies in solid organ adult recipients: an analysis of the U.S. National Transplant Database. Transplantation. 2012;94(10): 990-998.

19. Hall EC, Pfeiffer RM, Segev DL, Engels EA. Cumulative incidence of cancer after solid organ transplantation. Cancer. 2013;119(12): 2300-2308. 
Table 1. Patient demographics, with stratification by the incidence of post transplant cutaneous and non-cutaneous head and neck cancer.

\begin{tabular}{|c|c|c|c|c|c|c|}
\hline & Overall & $\begin{array}{l}\text { Any head ar } \\
\text { cancer }\end{array}$ & id neck & p-value & & \\
\hline & & Yes & No & $2 x$ & & \\
\hline Number $†$ & 1685 & $121(7 \%)$ & $1564(93 \%)$ & & & \\
\hline Recipient gender & & & & & & \\
\hline Male & $68 \%$ & $79 \%$ & $67 \%$ & $<0.01$ & & \\
\hline Recipient race & & & & & & \\
\hline White & $89 \%$ & $98 \%$ & $88 \%$ & $<0.01$ & & \\
\hline Recipient age $†$ (years) & 55 & 59 & 54 & $<0.001$ & & \\
\hline Recipient BMI & 28.1 & 27.6 & 28.1 & 0.36 & & \\
\hline Recipient model for end-stage & & & & & & \\
\hline liver disease score (MELD) † & 18 & 17 & 18 & $<0.01$ & & \\
\hline Retransplant & $2 \%$ & $2 \%$ & $2 \%$ & 0.91 & & \\
\hline & $\begin{array}{l}\text { Any cuta } \\
\text { and neck }\end{array}$ & $\begin{array}{l}\text { eous head } \\
\text { ancer }\end{array}$ & p-value & $\begin{array}{l}\text { Any non } \\
\text { head an } \\
\text { cancer }\end{array}$ & $\begin{array}{l}\text { taneol } \\
\text { eck }\end{array}$ & p-value \\
\hline & Yes & No & & Yes & No & \\
\hline Number $\dagger$ & $103(6 \%)$ & $1582(94 \%)$ & & $25(1 \%)$ & 1660 & \\
\hline Recipient gender & & & & & & \\
\hline Male & $80 \%$ & $67 \%$ & $<0.01$ & $80 \%$ & $67 \%$ & 0.18 \\
\hline Recipient race & & & & & & \\
\hline White & $100 \%$ & $88 \%$ & 0.001 & $88 \%$ & $89 \%$ & 0.26 \\
\hline Recipient age $\dagger$ (years) & 59 & 54 & $<0.001$ & 54 & 55 & 0.70 \\
\hline Recipient BMI† & 28.3 & 28.1 & 0.79 & 25.5 & 28.1 & 0.02 \\
\hline Recipient model for end-stage & & & & & & \\
\hline liver disease score (MELD) † & 17 & 18 & $<0.01$ & 15 & 18 & 0.10 \\
\hline Retransplant & $2 \%$ & $2 \%$ & 0.90 & $0 \%$ & $2 \%$ & 0.50 \\
\hline
\end{tabular}


Table 2. Incidence of post transplant cutaneous and non-cutaneous head and neck cancer stratified by patient demographics.

\begin{tabular}{|c|c|c|c|c|c|c|}
\hline & $\begin{array}{l}\text { Any } \\
\text { cutaneous } \\
\text { head and } \\
\text { neck } \\
\text { cancer }\end{array}$ & $p$-value & $\begin{array}{l}\text { Any non- } \\
\text { cutaneous } \\
\text { head and } \\
\text { neck cancer }\end{array}$ & $p$-value & $\begin{array}{l}\text { Any head } \\
\text { and neck } \\
\text { cancer }\end{array}$ & $p$-value \\
\hline $\begin{array}{l}\text { Number } \dagger \\
\text { Recipient gender }\end{array}$ & $103(6 \%)$ & & $25(1 \%)$ & & $121(7 \%)$ & \\
\hline Male & $7.2 \%$ & 0.01 & $1.8 \%$ & 0.20 & $8.4 \%$ & $<0.01$ \\
\hline Female & $3.8 \%$ & & $0.9 \%$ & & $4.6 \%$ & \\
\hline Recipient race & & & & & & \\
\hline White & $6.9 \%$ & 0.001 & $1.5 \%$ & 0.26 & $7.9 \%$ & $<0.01$ \\
\hline Black & $0.0 \%$ & & $2.9 \%$ & & $2.9 \%$ & \\
\hline Other & $0.0 \%$ & & $0.0 \%$ & & $0.0 \%$ & \\
\hline Recipient age (median) & & & D & & & \\
\hline$<30$ years & $0.0 \%$ & $<0.001$ & $1.8 \%$ & 0.95 & $1.8 \%$ & $<0.001$ \\
\hline 30 to 39 years & $2.4 \%$ & & $1.2 \%$ & & $3.6 \%$ & \\
\hline 40 to 49 years & $1.6 \%$ & & $1.9 \%$ & & $3.0 \%$ & \\
\hline 50 to 59 years & $6.6 \%$ & & $1.3 \%$ & & $7.8 \%$ & \\
\hline $\begin{array}{c}60 \text { years and older } \\
\text { Recipient BMI (median) }\end{array}$ & $10.0 \%$ & & $1.4 \%$ & & $10.6 \%$ & \\
\hline Less than 25.0 & $6.3 \%$ & 0.61 & $2.5 \%$ & 0.25 & $7.9 \%$ & 0.79 \\
\hline 25.0 to 29.9 & $5.8 \%$ & & $1.3 \%$ & & $6.9 \%$ & \\
\hline 30.0 to 34.9 & $7.5 \%$ & & $0.9 \%$ & & $8.0 \%$ & \\
\hline 35.0 and higher & $4.9 \%$ & & $1.1 \%$ & & $6.0 \%$ & \\
\hline \multicolumn{7}{|c|}{ Recipient MELD at transplant (median) } \\
\hline Less than 20 & $7.1 \%$ & 0.01 & $1.8 \%$ & 0.47 & $8.3 \%$ & 0.01 \\
\hline 20 to 29 & $6.5 \%$ & & $1.7 \%$ & & $7.7 \%$ & \\
\hline 30 and higher & $1.1 \%$ & & $0.5 \%$ & & $1.6 \%$ & \\
\hline
\end{tabular}


Table 3. Incidence of post-transplant head and neck cancers, stratified by patient history of tobacco use and alcohol abuse, and previous history of other cancers.

\begin{tabular}{|c|c|c|c|c|c|c|c|}
\hline & Overall & $\begin{array}{l}\text { Any cutaneous } \\
\text { head and neck } \\
\text { cancer }\end{array}$ & p-value & $\begin{array}{l}\text { Any non- } \\
\text { cutaneous head } \\
\text { and neck cancer }\end{array}$ & p-value & $\begin{array}{l}\text { Any head and } \\
\text { neck cancer }\end{array}$ & p-value \\
\hline \multicolumn{8}{|c|}{ Documented alcohol abuse } \\
\hline Yes & $607(37 \%)$ & $40(39 \%)$ & 0.71 & $18(72 \%)$ & $<0.001$ & $54(45 \%)$ & 0.08 \\
\hline No & $1027(63 \%)$ & $63(61 \%)$ & & $7(28 \%)$ & & $67(55 \%)$ & \\
\hline \multicolumn{8}{|l|}{ Tobacco use } \\
\hline Never smoker & $833(49 \%)$ & $52(50 \%)$ & 0.83 & 8 (32\%) & 0.05 & $56(46 \%)$ & 0.47 \\
\hline Ever smoker & $852(51 \%)$ & $51(50 \%)$ & & $17(68 \%)$ & & $65(54 \%)$ & \\
\hline \multicolumn{8}{|c|}{$\begin{array}{l}\text { Estimated tobacco exposure } \\
\text { (pack-years) }\end{array}$} \\
\hline Zero & $863(51 \%)$ & $56(54 \%)$ & $<0.01$ & $8(32 \%)$ & $<0.01$ & $61(50 \%)$ & 0.001 \\
\hline 1 to 19 & $242(14 \%)$ & $5(5 \%)$ & & $1(4 \%)$ & & $6(5 \%)$ & \\
\hline More than 40 & $149(9 \%)$ & $16(16 \%)$ & & $6(24 \%)$ & & $20(17 \%)$ & \\
\hline \multicolumn{8}{|c|}{ Pre-transplant history of any non-liver cancer } \\
\hline Yes & $161(10 \%)$ & $14(14 \%)$ & 0.15 & $2(8 \%)$ & 0.79 & $16(13 \%)$ & 0.15 \\
\hline No & $1524(90 \%)$ & $89(86 \%)$ & & $23(92 \%)$ & & $105(87 \%)$ & \\
\hline \multicolumn{8}{|c|}{ Pre-transplant history of non-cutaneous head and neck cancer } \\
\hline Yes & $12(1 \%)$ & $0(0 \%) \quad 1$. & & $0(0 \%)$ & 1.00 & $0(0 \%)$ & 1.00 \\
\hline No & $1673(99 \%)$ & $103(100 \%)$ & & $2(100 \%)$ & & $121(100 \%)$ & \\
\hline \multicolumn{8}{|c|}{ History of hepatocellular carcinoma } \\
\hline Yes & $393(23 \%)$ & $26(25 \%)$ & & $5(20 \%)$ & 0.69 & $29(24 \%)$ & 0.86 \\
\hline No & $1292(77 \%)$ & 77 (75\%) & & $20(80 \%)$ & & 92 (76\%) & \\
\hline
\end{tabular}


Table 4. Head and neck cancers by location and type in 1685 liver transplant patients. $\dagger$

\begin{tabular}{|c|c|c|c|c|c|}
\hline & Overall & BCC & ScC & Melanoma & Basosquamous \\
\hline $\begin{array}{l}\text { Number of patients (\% overall) with } \\
\text { cutaneous head and neck cancer }\end{array}$ & $103(6 \%)$ & $48(3 \%)$ & $57(3 \%)$ & $4(<1 \%)$ & $1(<1 \%)$ \\
\hline \multicolumn{6}{|l|}{ Locations of cutaneous cancers $\ddagger$} \\
\hline Scalp & $15(1 \%)$ & 6 & 11 & 1 & 0 \\
\hline Nose & $25(2 \%)$ & 20 & 11 & 0 & 1 \\
\hline Cheek/Mandible & $22(1 \%)$ & 9 & 15 & 0 & 0 \\
\hline Ear & $18(1 \%)$ & 11 & 8 & 0 & 0 \\
\hline Eyelid & $5(<1 \%)$ & 3 & 3 & 0 & 0 \\
\hline Chin & $2(<1 \%)$ & 1 & 1 & 0 & 0 \\
\hline Forehead & $18(1 \%)$ & 9 & 14 & 0 & 0 \\
\hline Temple & $8(<1 \%)$ & 2 & 6 & 1 & 0 \\
\hline Lip & $4(<1 \%)$ & 2 & 3 & 0 & 0 \\
\hline Neck & $15(1 \%)$ & 6 & 9 & 2 & 0 \\
\hline \multicolumn{6}{|c|}{$\begin{array}{l}\text { Number of patients (\%) with non-cutaneous } \\
\text { head and neck cancer }\end{array}$} \\
\hline \multicolumn{6}{|c|}{ Locations of non-cutaneous cancers } \\
\hline Larynx & 7 & & & & \\
\hline Sternocleidomastoid & 1 & & & & \\
\hline Thryroid & 2 & & & & \\
\hline Oral Cavity & 5 & & & & \\
\hline Nasopharynx & 0 & & & & \\
\hline Oropharynx & 4 & & & & \\
\hline Hypopharynx & 5 & & & & \\
\hline Salivary Gland & 4 & & & & \\
\hline
\end{tabular}


Figure 1a. Cox regression 10-year patient survival post liver transplant for patients with cutaneous head and neck cancer compared to all other patients.

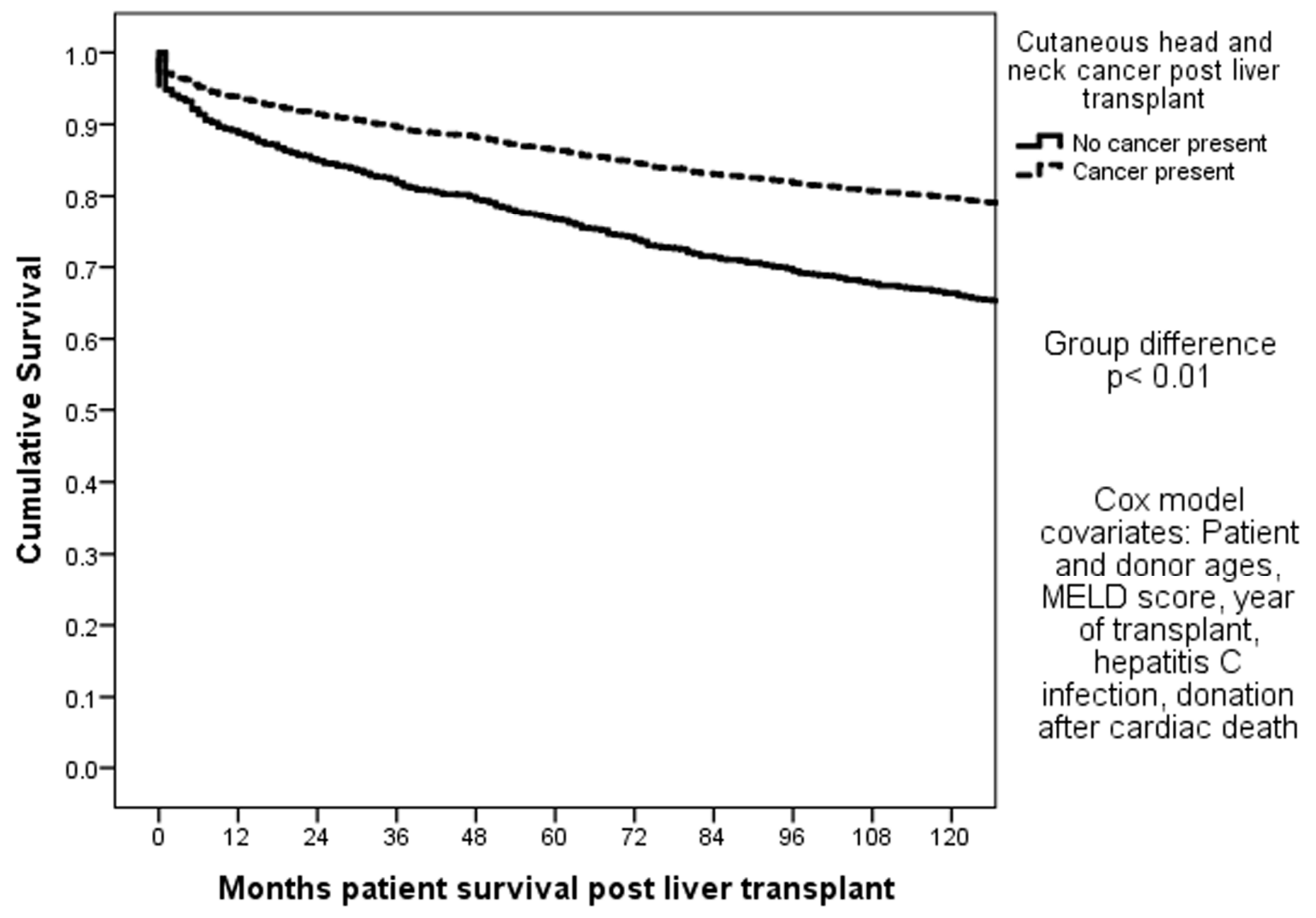


Figure 1b. Cox regression 10-year patient survival post liver transplant for patients with non-cutaneous head and neck cancer compared to all other patients.

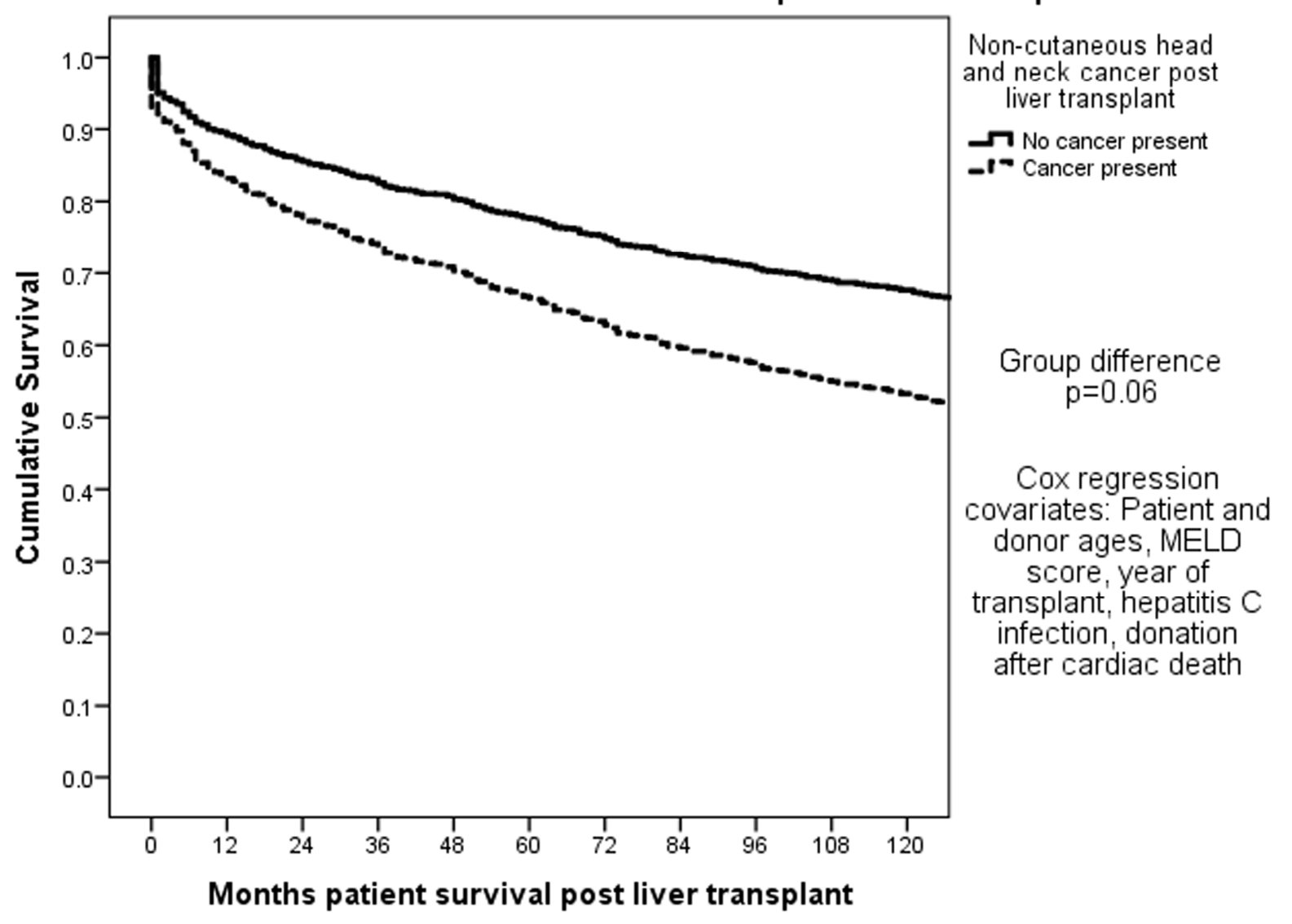

